\title{
Stress-Strain behaviour of plain and fibre reinforced SCC mixes
}

\author{
$U$ Prashanth $^{1 *}, S$ Shrihari $^{2}, V$ Siva Prasad Raju ${ }^{3}$, and Srinivasa Reddy $\mathrm{V}^{4}$ \\ ${ }^{1} \mathrm{M}$. Tech (Structural Engineering), Department of Civil Engineering, VJIT, Hyderabad, India. \\ ${ }^{2}$ Professor of Civil Engineering, VJIT, Hyderabad, India. \\ ${ }^{3}$ Assistant Professor of Civil Engineering, GRIET, Hyderabad, India. \\ ${ }^{4}$ Professor of Civil Engineering, GRIET, Hyderabad, India.
}

\begin{abstract}
The goal of this research is to better understand the stress-strain behaviour of plain and fibre reinforced M30 grade plain SCC mixtures. The experimental stress strain relationship of SCC revealed that all changes had a minor effect on the stress strain curve's first section. The stress-strain behaviour of M30 FRSCC mixtures has improved with the addition of fibres, resulting in lower stress values for the same stresses. At peak loads, all fibre reinforced SCC mixes, notably SFRSCC and HFRSCC mixes, showed an increase in strain values. Steel and hybrid fibres enhanced the postpeak stress-strain behaviour of SCC mixes compared to glass fibered SCC mixes. M30 grades' modulus of elasticity When compared to other FRSCC mixes, HFRSCC mixes created with optimal combinations of $\mathrm{PF}$ and s/a ratios have high values. By dispersing deformation energy through fibres, HFRSCC mixtures have a better capacity to prevent fracture growth. HFRSCC mixtures with high toughness moduli have better shock resistance. Because of the dense and compact microstructure, the modulus of elasticity (E) of HFRSCC mixes shows improved performance.
\end{abstract}

\section{Introduction}

European Federation of National Associations Representing for Concrete (EFNARC)(2002) has developed specifications and guidelines for the use of SCC that covers a number of topics ranging from material selection and mixture design to the significance of the testing methods. The main disadvantage of SCC is the high cost associated with the use of chemical admixtures and high volumes of Portland cement. SCC can be obtained by increasing the fine aggregate content; by limiting the maximum aggregate size; by increasing the powder content; by using viscosity modifying admixtures (VMA) and reducing the water-to-binder ratio through superplasticizer (SP).

\section{Stress -strain studies}

Stress-strain behaviour was investigated for plain, steel fibred reinforced (SFR), glass fibred reinforced (GFR), and hybrid fibred reinforced (HFR) M30

\footnotetext{
* Corresponding author: prashanth.ulirao.09@gmail.com
}

grade self-compacting concrete (SCC) mixes, and characteristics such as modulus of elasticity and toughness were determined. Validate experimental stress-strain results against theoretical stress-strain values calculated using the Seanz analytical model. The cylinders were tested at 28 days for stress strain behaviour under strain controlled uniaxial compression testing machine. The experimental stress-strain behaviour for all plain and SCC mixes was plotted.

The stress - strain behaviour of M30 grade PSCC, SFRSCC, GFRSCC and HFRSCC mixes was found to be almost similar. However, it is observed that the addition of fibres has improved the peak stress values for the same strains. Increase in strain values were observed at peak stresses in all fibre reinforced SCC mixes especially more in SFRSCC and HFRSCC mixes. Addition of steel and hybrid fibres improved the post-peak stress-strain behaviour in SCC mixes than glass fibred SCC mixes.

The inclusion of fibres causes the FRSCC to become more ductile by increasing the strain corresponding to peak stress. It can be shown that the SFRSCC and HFRSCC mixes have higher ultimate load-carrying 
capacity and strains at peak stresses than the GFRSCC mix. The inclusion of steel and glass fibres increases the strength-carrying capacity and allows for greater strains to be handled during peak pressures, as can be observed.

Table 1. M30 grade PSCC, SFRSCC, GFRSCC, and HFRSCC stress-strain behaviour for the best combination of PF=1.12 and $\mathrm{s} / \mathrm{a}=0.53$

\begin{tabular}{|c|c|c|c|c|c|c|c|}
\hline \multicolumn{2}{|c|}{ Plain SCC } & \multicolumn{2}{c|}{ GFRSCC } & \multicolumn{2}{c|}{ SFRSCC } & \multicolumn{2}{c|}{ HFRSCC } \\
\hline Strain & Stress & Strain & Stress & Strain & Stress & Strain & Stress \\
\hline 0.0000 & 0.00 & 0.0000 & 0.00 & 0.0000 & 0.00 & 0.0000 & 0.00 \\
\hline 0.0001 & 3.01 & 0.0000 & 0.17 & 0.0002 & 6.43 & 0.0000 & 0.58 \\
\hline 0.0003 & 6.18 & 0.0002 & 5.57 & 0.0003 & 10.91 & 0.0001 & 4.08 \\
\hline 0.0004 & 9.86 & 0.0003 & 9.91 & 0.0004 & 15.19 & 0.0002 & 9.34 \\
\hline 0.0006 & 13.37 & 0.0005 & 14.09 & 0.0006 & 19.09 & 0.0002 & 12.84 \\
\hline 0.0008 & 17.55 & 0.0007 & 17.39 & 0.0008 & 24.35 & 0.0004 & 17.11 \\
\hline 0.0010 & 22.39 & 0.0009 & 22.09 & 0.0010 & 27.66 & 0.0005 & 19.83 \\
\hline 0.0012 & 25.57 & 0.0010 & 24.35 & 0.0011 & 30.00 & 0.0006 & 22.93 \\
\hline 0.0015 & 29.08 & 0.0011 & 27.48 & 0.0012 & 33.51 & 0.0007 & 25.07 \\
\hline 0.0016 & 32.42 & 0.0012 & 27.65 & 0.0014 & 36.62 & 0.0008 & 27.20 \\
\hline 0.0018 & 34.27 & 0.0013 & 32.00 & 0.0015 & 38.96 & 0.0009 & 29.73 \\
\hline 0.0021 & 35.11 & 0.0013 & 33.74 & 0.0017 & 38.57 & 0.0010 & 31.86 \\
\hline 0.0023 & 34.96 & 0.0014 & 35.65 & 0.0019 & 36.43 & 0.0012 & 33.80 \\
\hline 0.0025 & 33.80 & 0.0015 & 34.96 & 0.0021 & 32.73 & 0.0013 & 35.54 \\
\hline 0.0027 & 30.48 & 0.0017 & 33.04 & 0.0022 & 29.42 & 0.0015 & 39.03 \\
\hline 0.0029 & 27.50 & 0.0019 & 30.43 & 0.0023 & 28.64 & 0.0016 & 41.16 \\
\hline 0.0031 & 23.67 & 0.0022 & 15.00 & 0.0025 & 24.94 & 0.0018 & 39.01 \\
\hline 0.0032 & 21.01 & & & 0.0025 & 22.60 & 0.0019 & 35.30 \\
\hline 0.0035 & 18.53 & & & 0.0026 & 19.68 & 0.0020 & 32.17 \\
\hline 0.0036 & 16.03 & & & & & 0.0021 & 30.02 \\
\hline 0.0038 & 15.54 & & & & & 0.0022 & 26.12 \\
\hline & & & & & & 0.0023 & 22.22 \\
\hline
\end{tabular}

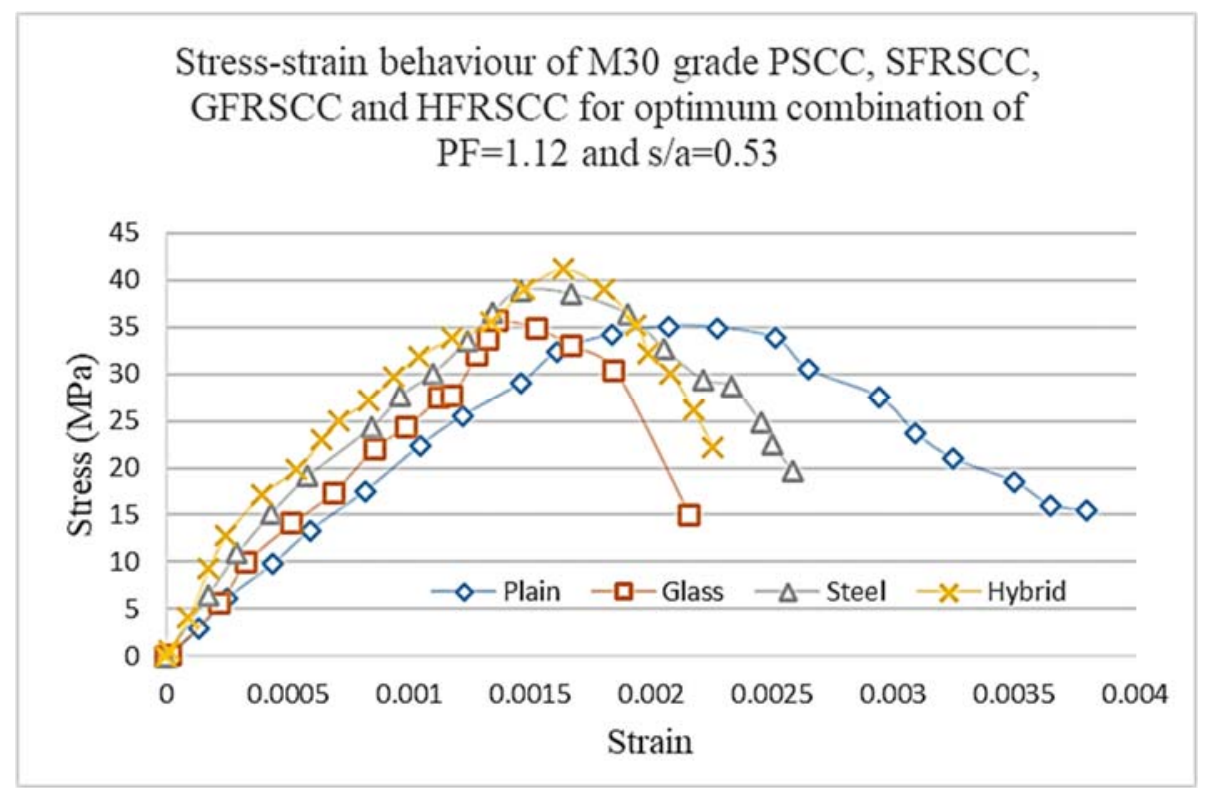

Fig.1. M30 grade PSCC, SFRSCC, GFRSCC, and HFRSCC stress-strain curves for the best combination of PF=1.12 and $\mathrm{s} / \mathrm{a}=0.53$ 
Table 2. M30 grade PSCC, SFRSCC, GFRSCC, and HFRSCC stress-strain behaviour for the best combination of PF=1.14

\begin{tabular}{|c|c|c|c|c|c|c|c|}
\hline \multicolumn{2}{|c|}{ Plain SCC } & \multicolumn{2}{c|}{ GFRSCC } & \multicolumn{2}{c|}{ SFRSCC } & \multicolumn{2}{c|}{ HFRSCC } \\
\hline Strain & Stress & Strain & Stress & Strain & Stress & Strain & Stress \\
\hline 0.0000 & 0.00 & 0.0000 & 0.00 & 0.0000 & 0.00 & 0.0000 & 0.00 \\
\hline 0.0000 & 0.17 & 0.0001 & 3.52 & 0.0000 & 0.65 & 0.0001 & 3.88 \\
\hline 0.0000 & 0.34 & 0.0003 & 6.46 & 0.0001 & 4.33 & 0.0003 & 9.28 \\
\hline 0.0001 & 4.48 & 0.0005 & 10.37 & 0.0002 & 8.44 & 0.0005 & 13.59 \\
\hline 0.0003 & 8.97 & 0.0010 & 16.83 & 0.0003 & 11.47 & 0.0006 & 18.13 \\
\hline 0.0005 & 12.59 & 0.0012 & 20.74 & 0.0004 & 14.07 & 0.0007 & 22.01 \\
\hline 0.0007 & 16.72 & 0.0016 & 24.85 & 0.0005 & 16.67 & 0.0010 & 25.02 \\
\hline 0.0008 & 20.52 & 0.0018 & 28.37 & 0.0006 & 19.05 & 0.0010 & 28.48 \\
\hline 0.0010 & 23.62 & 0.0021 & 32.48 & 0.0007 & 21.65 & 0.0013 & 32.57 \\
\hline 0.0012 & 27.24 & 0.0024 & 35.41 & 0.0009 & 25.32 & 0.0014 & 35.59 \\
\hline 0.0013 & 29.48 & 0.0025 & 35.80 & 0.0010 & 29.87 & 0.0016 & 37.95 \\
\hline 0.0016 & 34.48 & 0.0028 & 40.11 & 0.0011 & 32.90 & 0.0018 & 40.96 \\
\hline 0.0017 & 36.90 & 0.0031 & 40.11 & 0.0013 & 35.28 & 0.0020 & 43.54 \\
\hline 0.0019 & 36.90 & 0.0034 & 38.93 & 0.0014 & 38.10 & 0.0020 & 44.19 \\
\hline 0.0021 & 34.66 & 0.0038 & 35.41 & 0.0016 & 41.99 & 0.0022 & 43.74 \\
\hline 0.0022 & 31.38 & 0.0040 & 31.89 & 0.0016 & 42.86 & 0.0024 & 42.43 \\
\hline 0.0023 & 28.28 & 0.0042 & 28.76 & 0.0018 & 40.04 & 0.0026 & 39.16 \\
\hline 0.0025 & 25.86 & 0.0044 & 25.83 & 0.0019 & 34.63 & 0.0028 & 35.03 \\
\hline 0.0025 & 24.14 & 0.0045 & 24.07 & 0.0021 & 29.00 & 0.0029 & 32.42 \\
\hline 0.0026 & 22.07 & & & 0.0022 & 22.08 & 0.0030 & 30.68 \\
\hline & & & & 0.0023 & 16.67 & & \\
\hline & & & & 0.0024 & 12.55 & & \\
\hline
\end{tabular}

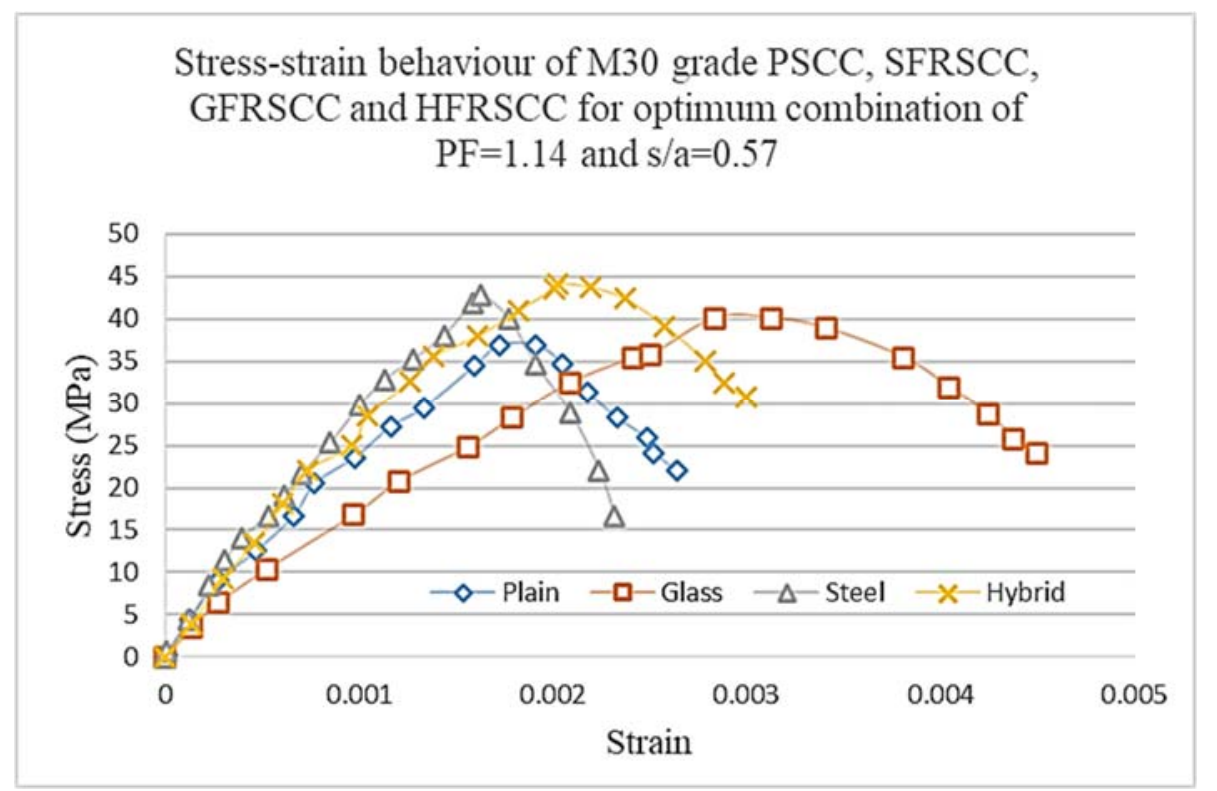

Fig.2. M30 grade PSCC, SFRSCC, GFRSCC, and HFRSCC stress-strain curves for the best combination of PF=1.14 and $\mathrm{s} / \mathrm{a}=0.57$ 


\section{Modulus of Elasticity and Toughness}

The secant modulus of elasticity and toughness of M30 grade PSCC, SFRSCC, GFRSCC, and HFRSCC mixes for optimal PF and s/a ratio combinations are shown in table 3.

Table3. M30 grade PSCC, SFRSCC, GFRSCC, HFRSCC mixes' modulus of elasticity and toughness for optimal PF and s/a ratio combinations

\begin{tabular}{|c|c|c|c|}
\hline Mix type & Optimum PFs and s/a ratios & $\begin{array}{l}\text { Secant modulus of } \\
\text { Elasticity } \\
(\mathrm{GPa})\end{array}$ & $\begin{array}{c}\text { Toughness } \\
\text { (MPa) }\end{array}$ \\
\hline M30PSCC & \multirow{4}{*}{$\begin{array}{l}\mathrm{PF}=1.12 \\
\quad \text { and } \\
\mathrm{s} / \mathrm{a}=0.53\end{array}$} & 31.4 & 0.04025 \\
\hline M30SFRSCC & & 37.5 & 0.05805 \\
\hline M30GFRSCC & & 34.4 & 0.04440 \\
\hline M30HFRSCC & & 38.8 & 0.05903 \\
\hline M30PSCC & \multirow{4}{*}{$\begin{array}{l}\mathrm{PF}=1.14 \\
\quad \text { and } \\
\mathrm{s} / \mathrm{a}=0.57\end{array}$} & 31.8 & 0.04124 \\
\hline M30SFRSCC & & 38.2 & 0.06007 \\
\hline M30GFRSCC & & 35.7 & 0.04536 \\
\hline M30HFRSCC & & 38.9 & 0.06109 \\
\hline
\end{tabular}

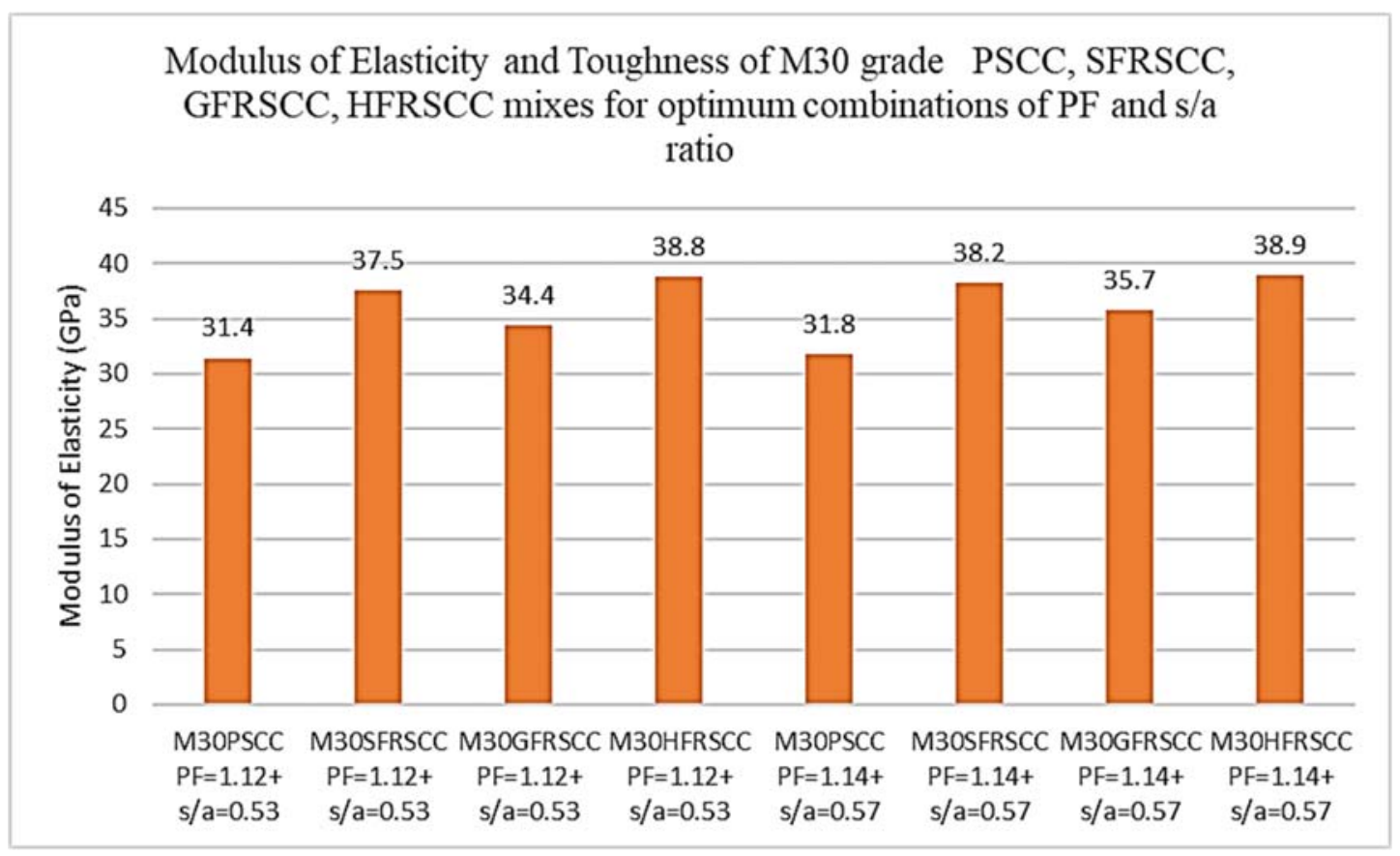

Fig.1. Modulus of Elasticity and Toughness of M30 grade PSCC, SFRSCC, GFRSCC, HFRSCC mixes for optimum combinations of $\mathrm{PF}$ and s/a ratio

The modulus of elasticity describes the material's elastic behaviour, whereas toughness describes a material's capacity to resist fracture development by dispersing deformation energy. The slope of the stress-strain curve may be used to calculate modulus of elasticity, whereas the area (i.e., the integral) beneath the stress-strain curve can be used to measure toughness (the amount of energy absorbed by the specimen under loading). Due to its improved ability to resist fracture propagation by dispersing deformation energy through fibres, M30 grade fibre reinforced SCC mixes have a higher toughness or energy absorption capacity than equivalent grades of plain SCC mixes. Fibre reinforced SCC mixtures with high toughness moduli provide better shock resistance. The modulus of elasticity (E) of fibre reinforced SCC mixes is found to be higher in all classes, suggesting improved performance due to the dense and compact microstructure of fibre reinforced SCC mixes. 


\section{Conclusions}

The following conclusions are reached based on the findings provided in this study work and significant discoveries during the experimental investigations:

1. Based on the Nan Su mix design principles and subjected to the EFNARC flow standards, M30 grade plain SCC mixes are designed with various combinations of packing factors (PF) (ranging from 1.12 to 1.18) and fine to total aggregate ratios $(\mathrm{s} / \mathrm{a})(0.50,0.53$, and 0.57$)$.

2. The PF \& s/a combinations $1.12 \& 0.53$ and 1.14 $\& 0.57$ were found to be the most effective, resulting in the highest compressive strengths, which can be related to the high particle packing densities achieved in SCC mixtures.

3. These optimum combinations of packing factors and s/a ratio is further used in the development of the fibre reinforced SCC mixes of grade M30.

4. The experimental stress strain relationship of SCC revealed that all changes had a minor effect on the stress strain curve's first section. The stress-strain behaviour of M30 FRSCC mixtures has improved with the addition of fibres, resulting in lower stress values for the same stresses. At peak loads, all fibre reinforced SCC mixes, notably SFRSCC and HFRSCC mixes, showed an increase in strain values. Steel and hybrid fibres enhanced the post-peak stressstrain behaviour of SCC mixes compared to glass fibered SCC mixes.

5. M30 grades' modulus of elasticity When compared to other FRSCC mixes, HFRSCC mixes created with optimal combinations of PF and s/a ratios have high values.

6. By dispersing deformation energy through fibres, HFRSCC mixtures have a better capacity to prevent fracture growth. HFRSCC mixtures with high toughness moduli have better shock resistance. Because of the dense and compact microstructure, the modulus of elasticity (E) of HFRSCC mixes shows improved performance.

\section{References}

1. Srinivas. T, Abhignya. G and Ramana Rao. N.V, A Review on Geopolymer RCC Beams made with Recycled Coarse Aggregate, E3S Web of Conferences, ICMED, 10-12 July 2020, India (2020).

2. T. Srinivas, S. V. Srinidhi and N.V. Ramana Rao, A Review on Flexural Behavior of RCC Beams Made with Geopolymer Concrete, E3S Web of Conferences, ICMED, 10-12 July 2020, India (2020).

3. M. Kavitha, P. B. Bobba and D. Prasad, 2016 IEEE 6th International Conference on Power Systems (ICPS), 2016, pp. 1-6
4. T. Srinivas , P. Bhavana, and N. V. Ramana Rao, Effect of Manufactured Sand on Flexural Behavior of Geopolymer RCC Beams: A review, E3S Web of Conferences, ICMED, 10-12 July 2020, India (2020).

5. T. Srinivas and N.V.Ramana Rao, IJCIET, Volume 10, 510 (2019).

6. K. Sai Gopi, Dr. T. Srinivas and S. P. Raju V, E3S Web of Conferences ICMED 184, 01084GRIET, 28-29 (2020)

7. Jagannadha Kumar, M.V., Jagannadha Rao, K., Dean Kumar, B., Srinivasa Reddy, V., Int. J. of Civil Eng. and Tech., 9(7), pp. 1133-1141 (2018)

8. Ganta, J.K., Seshagiri Rao, M.V., Mousavi, S.S., Srinivasa Reddy, V., Bhojaraju, C., Structures 28, pp. 956-972 (2020)

9. Kavitha, Merugu; Prasad, Dinkar; Bobba, Phaneendra Babu: IET Electric Power Applications, 2019, 13, (8), p. 1184-1192

10. Naidu, K.S.S.T., Rao, M.V.S., Reddy, V.S., Int. J. of Innov. Tech. and Explor. Eng.g (IJITEE), 8(9 Special Issue 2), pp. 641-642 (2019)

11. Chandana Priya, C., Seshagiri Rao, M.V., Srinivasa Reddy, V., Int. J. of Civil Eng. and Tech., 9(11), pp. 2218-2225 (2018)

12. Satya Sai Trimurty Naidu, K., Seshagiri Rao, M.V., Srinivasa Reddy, V., Int. J. of Civil Eng. and Tech., 9(11), pp. 2383-2393 (2018)

13. Supriya, Y., Srinivasa Reddy, V., Seshagiri Rao, M.V., Shrihari, S., Int. J. of Rec. Tech. and Engi., 8(3), pp. 5381-5385 (2019)

14. Kotkunde, N., Krishna, G., Shenoy, S.K., Gupta, A.K., Singh, S.K. International Journal of Material Forming, 10 (2), pp. 255-266 (2017)

15. K. Satyanarayana, A. V. Gopal, and P.B. Babu, Proceedings of the Institution of Mechanical Engineers, Part C: Journal of Mechanical Engineering Science, 228(1), 152 (2014)

16. Govardhan, D., Kumar, A.C.S., Murti, K.G.K., Madhusudhan Reddy, G. Materials and Design, 36, pp. 206-214. (2012)

17. Kumar, P., Singhal, A., Mehta, S., Mittal, A. Journal of Real-Time Image Processing, 11 (1), pp. 93-109. (2016)

18. Srinivas Rao J, S K Tummala, Kuthuri N R, Indonesia Journal of Electrical Engg. \& Computer Science, 21 (723), 2020

19. Raghunadha Reddy, T., Vishnu Vardhan, B., Vijayapal Reddy, P. International Journal of Applied Engineering Research, 11 (5), pp. 30923102 (2016)

20. Hussaini, S.M., Krishna, G., Gupta, A.K., Singh, S.K. Journal of Manufacturing Processes, 18, pp. 151-158 (2015) 